\title{
Solid-phase enrichment and analysis of electrophilic natural products
}

\author{
Frank Wesche ${ }^{1}$, Yue He${ }^{1}$ and Helge B. Bode ${ }^{* 1,2}$
}

\section{Full Research Paper}

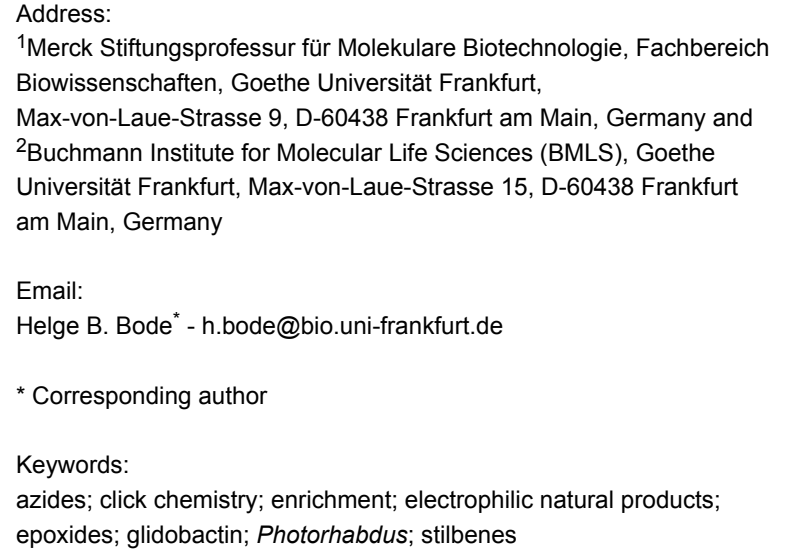

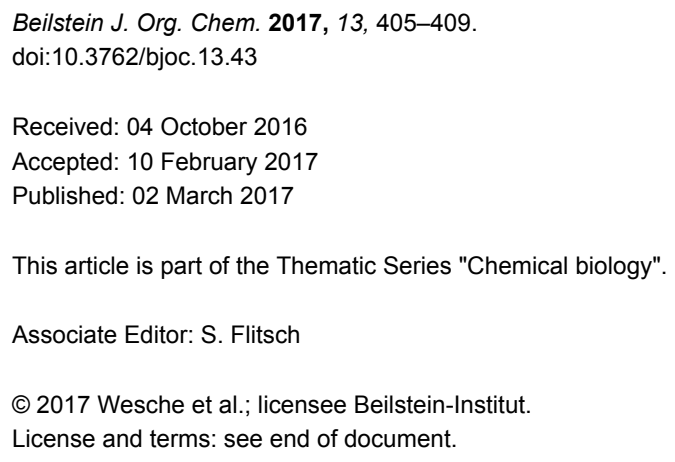

\begin{abstract}
In search for new natural products, which may lead to the development of new drugs for all kind of applications, novel methods are needed. Here we describe the identification of electrophilic natural products in crude extracts via their reactivity against azide as a nucleophile followed by their subsequent enrichment using a cleavable azide-reactive resin (CARR). Using this approach, natural products carrying epoxides and $\alpha, \beta$-unsaturated enones as well as several unknown compounds were identified in crude extracts from entomopathogenic Photorhabdus bacteria.
\end{abstract}

\section{Introduction}

Microorganisms are a major source for novel natural products and the subsequent development of new drugs for all kinds of applications [1,2]. For example, the discovery of the fungal natural product cyclosporine as an immunosuppressant drug facilitated modern organ transplantation $[3,4]$.

The increasing sensitivity of analytical methods, especially in mass spectrometry, enables the detailed analysis of various natural product producing microbes. Much more compounds have been identified than originally thought, but often these are produced only at a very low level. This is also reflected by the genome sequences of bacteria and fungi that often encode numerous biosynthesis gene clusters (BGC) with most of the corresponding natural products unknown for several reasons: these BGCs are silent under standard laboratory conditions [5], the compounds are too labile for isolation or they are produced in amounts still below the detection limit of modern mass spectrometers.

Therefore it is desirable to have multiple and complementary methods available that allow the detection of several different natural product classes. Besides the traditional chemical 
screening and bioactivity-guided isolation, the exploitation of the inherent properties of natural products is also feasible. Consequently, simple functional groups of natural products like dehydroalanine [6,7], ketones, aldehydes [8,9], carboxylic acids [8,9], amines [8-10], thiols [8,9], alcohols [11], epoxides [12], terminal alkynes $[13,14]$ and azides [15] can be targeted to introduce a label. Such labels might increase the visibility in UV or MS detection in liquid chromatography coupled to UV or mass spectrometry. Alternatively, natural products can be immobilized on reactive resins by making use of their chemical functionality and can be eluted after washing off all non-desired substances $[8,9,11,13,15]$.

The recently introduced cleavable azide-reactive resin (CARR (2), Scheme 1) is such a resin able to react with a broad range of

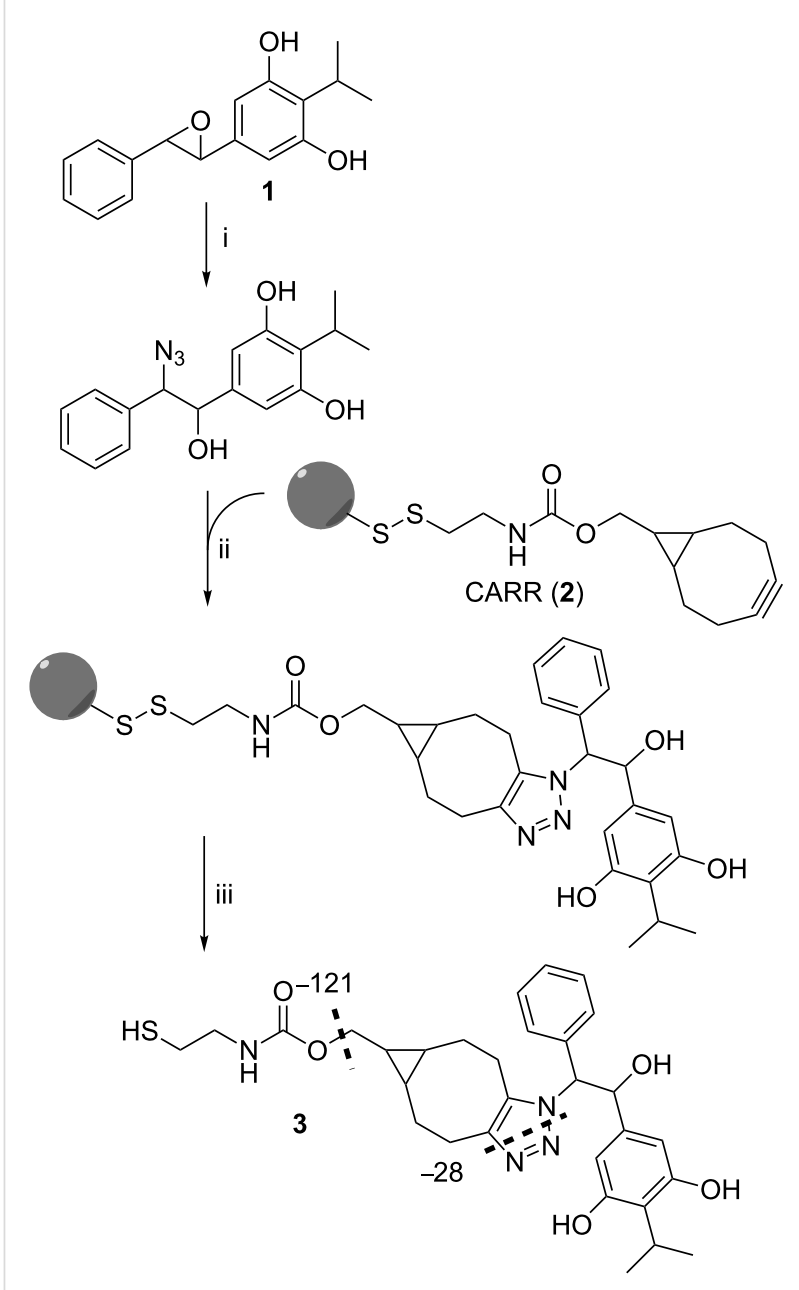

Scheme 1: Principle of azidation of XAD extracts from $P$. luminescens TT01 containing 1 and subsequent azide enrichment with CARR (2). After the vicinal azido alcohol is covalently bound to the resin through an azide-alkyne cycloaddition, compound 3 is cleaved from the resin and analyzed by HPLC-MS. Reaction conditions: i) $\mathrm{NaN}_{3}, \mathrm{NH}_{4} \mathrm{Cl}, 80 \%$ $\mathrm{MeOH}$ in $\mathrm{H}_{2} \mathrm{O}$, reflux overnight; ii) CARR (2), ACN, $55^{\circ} \mathrm{C}, 1 \mathrm{~h}$, then rt, overnight; iii) $5 \mathrm{mM}$ TCEP in PBS/CHCl $3 / \mathrm{MeOH}$ 1:5:10 (v/v/v), $1 \mathrm{~h}$. azides [15]. Thus, the metabolic fate of azide-containing biosynthesis intermediates or building blocks can be studied and natural products containing these azides can be identified.

Herein we describe the application of the CARR enrichment for the detection of electrophilic natural products using azide as the nucleophile. Indeed, we could detect epoxystilbene $\mathbf{1}$ and three glidobactins from different Photorhabdus strains and some of these compounds are produced in such low amounts that they are not detectable in standard crude extracts.

\section{Results and Discussion}

In order to evaluate whether the CARR approach is suitable for epoxide detection, we azidated commercially available transstilbene oxide as representative model compound for $\mathbf{1}$ affording the vicinal azido alcohol, 2-azido-1,2-diphenylethanol (Supporting Information File 1, Figure S2) [16,17]. The azidation was carried out with sodium azide and ammonium chloride in $80 \% \mathrm{MeOH}$ under reflux overnight (Supporting Information File 1, Figure S2). The azido alcohol was then incubated with CARR (2) in acetonitrile overnight followed by extensive washing of the resin with methanol and dichloromethane. After disulfide-bond cleavage with a solution of tris(2-carboxyethyl)phosphine (TCEP) in a 1:5:10 mixture of phosphatebuffered saline (PBS)/chloroform/methanol at $\mathrm{pH} 7$, the filtrate was analyzed by HPLC-MS. As expected the corresponding mass $m / z 493.2[\mathrm{M}+\mathrm{H}]^{+}$of the cleaved cycloaddition product could be directly detected in the base-peak chromatogram (BPC) showing the characteristic fragmentation pattern of the CARR adducts (Supporting Information File 1, Figure S3) [15]. Additionally, the detection limit of the model epoxide was investigated in a complex environment. For this, defined amounts of trans-stilbene oxide were added to liquid Lysogeny Broth (LB) medium. The obtained methanolic Amberlite XAD-16 extracts were azidated, enriched and analyzed. Up to a final concentration of $5 \mu \mathrm{g} / \mathrm{L}(\approx 25 \mathrm{nmol} / \mathrm{L})$ the epoxide could be detected (Supporting Information File 1, Figure S4). Following these results, we tested the method with an XAD extract of P. luminescens TT01 (Figure 1).

The obtained XAD extract was treated the same way as transstilbene oxide, and any potentially containing epoxide should be converted into the corresponding vicinal azido alcohol. Afterwards the azidated extract was incubated with $\mathbf{2}$, the disulfide bond was cleaved and the filtrate subsequently analyzed by HPLC-MS. To our surprise, the BPC showed one distinct peak at 8.1 min with a characteristic $\mathrm{MS}^{2}$ fragmentation pattern of a derivatized azide and a mass of $m / z 567.2[\mathrm{M}+\mathrm{H}]^{+}$. This mass corresponds to the calculated mass of 3 (Figure 1) derived from the derivatization of epoxystilbene $\mathbf{1}$, an oxidized isopropylstilbene derivative from this strain. Since only a single peak could 

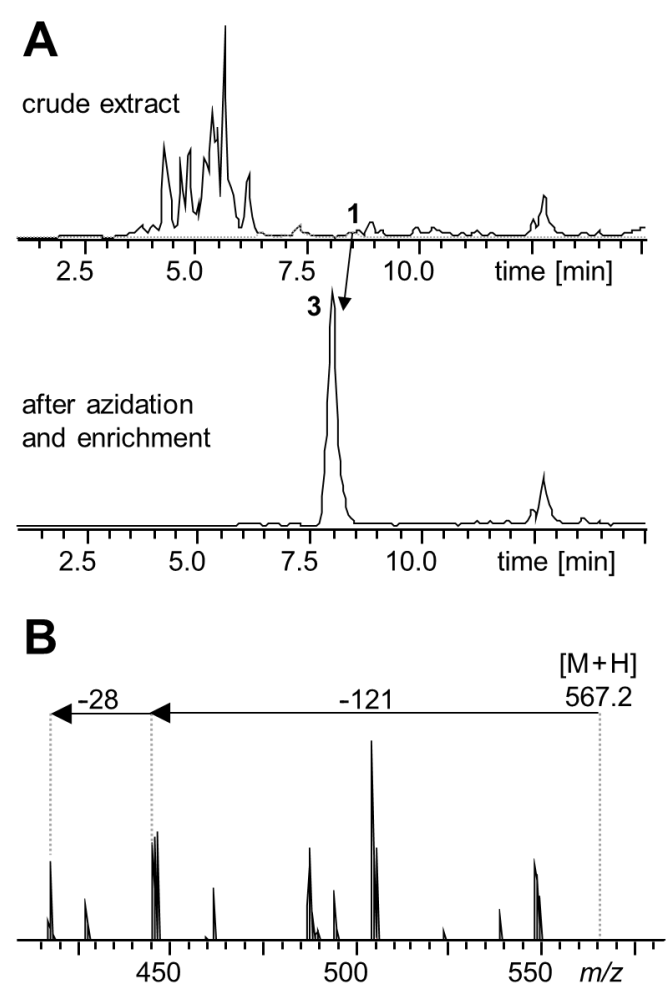

Figure 1: (A) HPLC-MS base peak chromatograms of a crude XAD extract of $P$. luminescens TT01 and after azidation and azide enrichment. The $t_{R}$ of 1 is indicated in the crude extract. After enrichment, one distinct peak at 8.1 min corresponding to 3 is visible. (B) The characteristic $\mathrm{MS}^{2}$ fragmentation pattern of the derivatized azide 3 is shown highlighting the neutral loss of carbamate $(-121)$ and dinitrogen $(-28)$ as characteristic fragments for CARR adducts.

be seen within the chromatogram, we assume that the conjugate addition took place only on the less hindered position in epoxide 1 without formation of the other possible regioisomer. For further structural confirmation, $P$. luminescens TT01 was cultivated in ${ }^{13} \mathrm{C}$-labeled medium prior to the azidation and enrichment procedure indeed confirming the incorporation of 17 carbon atoms in 3 (Supporting Information File 1, Figure S5). Furthermore, the molecular formula of the cleaved azide-alkyne cycloaddition product 3 was confirmed by HPLC-HRMS (calcd mass: $m / z$ 567.2636 $[\mathrm{M}+\mathrm{H}]^{+}$, found: $\mathrm{m} / z$ $567.2635[\mathrm{M}+\mathrm{H}]^{+}, \Delta \mathrm{ppm}=0.1$ ). Compound $\mathbf{1}$ could hardly be detected in extracts from standard growth media but was detected from infected insects and media mimicking the insect hemolymph [18-20]. Clearly the biosynthesis of this compound is strictly regulated and moreover it is a highly labile compound that is probably rapidly degraded [21]. Only a very weak signal of $\mathrm{m} / z 271.1[\mathrm{M}+\mathrm{H}]^{+}$could be detected at $8.5 \mathrm{~min}$, which can be associated with $\mathbf{1}$.

Encouraged by these results and especially the high sensitivity of the method, the azidation was performed with XAD extracts of three additional Photorhabdus strains (Photorhabdus PB45.5, Photorhabdus PB 68.1 and Photorhabdus temperata subsp. thracensis DSM 15199). Here, an even lower amount of 3 could be detected in Photorhabdus PB 68.1 (Supporting Information File 1, Figure S6), whereas in Photorhabdus PB45.5 and Photorhabdus temperata subsp. thracensis DSM 15199 nothing was visible at all, suggesting that the appropriate gene for the biosynthesis of $\mathbf{1}$ is either missing or silent in these species.

Upon a detailed look at the chromatograms, different masses with the characteristic fragmentation pattern of derivatized azides could be found (Table 1 and Supporting Information File 1, Figures S7-S9). The molecular formula obtained from HRMS data indicates that three glidobactin derivatives namely glidobactin A (4) [22], cepafungin I (5) [23,24] and luminmycin D (6) $[25,26]$ were enriched (Scheme 2). Glidobactins are well-known proteasome inhibitors that react with a conserved threonine residue in the $\beta 5$ subunit of the proteasome [24]. From Photorhabdus strains they have previously

\begin{tabular}{|c|c|c|c|c|c|c|c|c|}
\hline Strain & Compd. & $\begin{array}{l}t_{\mathrm{R}} \\
\min \end{array}$ & $\begin{array}{l}{[\mathrm{M}+\mathrm{H}]^{+}} \\
\text {found }\end{array}$ & $\begin{array}{l}\text { Calcd. molecular } \\
\text { formula }\end{array}$ & $\begin{array}{l}{[\mathrm{M}+\mathrm{H}]^{+}} \\
\text {calcd. }\end{array}$ & $\Delta \mathrm{ppm}$ & $\begin{array}{l}\text { Molecular } \\
\text { formula natural } \\
\text { product }\end{array}$ & $\begin{array}{l}\text { Natural } \\
\text { product }\end{array}$ \\
\hline $\begin{array}{l}\text { P. luminescens } \\
\text { TT01 }\end{array}$ & 3 & 8.1 & 567.2635 & $\mathrm{C}_{30} \mathrm{H}_{39} \mathrm{~N}_{4} \mathrm{O}_{5} \mathrm{~S}$ & 567.2636 & 0.1 & $\mathrm{C}_{17} \mathrm{H}_{18} \mathrm{O}_{3}$ & 1 \\
\hline \multirow{6}{*}{$\begin{array}{l}\text { Photorhabdus } \\
\text { PB } 68.1\end{array}$} & - & 8.6 & 491.2103 & $\mathrm{C}_{27} \mathrm{H}_{31} \mathrm{~N}_{4} \mathrm{O}_{3} \mathrm{~S}$ & 491.2071 & 2.2 & $\mathrm{C}_{14} \mathrm{H}_{10} \mathrm{O}$ & unknown \\
\hline & - & 8.0 & 493.2258 & $\mathrm{C}_{27} \mathrm{H}_{33} \mathrm{~N}_{4} \mathrm{O}_{3} \mathrm{~S}$ & 493.2268 & 2.0 & $\mathrm{C}_{14} \mathrm{H}_{12} \mathrm{O}$ & unknown \\
\hline & - & 8.5 & 517.2483 & $\mathrm{C}_{26} \mathrm{H}_{37} \mathrm{~N}_{4} \mathrm{O}_{5} \mathrm{~S}$ & 517.2479 & 2.0 & $\mathrm{C}_{13} \mathrm{H}_{16} \mathrm{O}_{3}$ & unknown \\
\hline & 3 & 8.1 & 567.2635 & $\mathrm{C}_{30} \mathrm{H}_{39} \mathrm{~N}_{4} \mathrm{O}_{5} \mathrm{~S}$ & 567.2636 & 0.1 & $\mathrm{C}_{17} \mathrm{H}_{18} \mathrm{O}_{3}$ & 1 \\
\hline & 7 & 9.0 & 817.4630 & $\mathrm{C}_{40} \mathrm{H}_{65} \mathrm{~N}_{8} \mathrm{O}_{8} \mathrm{~S}$ & 817.4641 & 2.0 & $\mathrm{C}_{27} \mathrm{H}_{44} \mathrm{~N}_{4} \mathrm{O}_{6}$ & 4 \\
\hline & 8 & 9.3 & 831.4801 & $\mathrm{C}_{41} \mathrm{H}_{67} \mathrm{~N}_{8} \mathrm{O}_{8} \mathrm{~S}$ & 831.4797 & 1.1 & $\mathrm{C}_{28} \mathrm{H}_{46} \mathrm{~N}_{4} \mathrm{O}_{6}$ & 5 \\
\hline
\end{tabular}


Table 1: Additionally found masses in the tested strains, calculated molecular formulas of possible azide-alkyne cycloaddition products, and the molecular formulas of the putative parent compounds derived from subtraction of the azide and CARR-derived moiety $\left(\mathrm{C}_{13} \mathrm{H}_{19} \mathrm{~N}_{4} \mathrm{O}_{2} \mathrm{~S}\right)$. (continued)

\begin{tabular}{|c|c|c|c|c|c|c|c|c|}
\hline \multirow{3}{*}{$\begin{array}{l}\text { Photorhabdus } \\
\text { PB } 45.5\end{array}$} & - & 10.7 & 551.3617 & $\mathrm{C}_{29} \mathrm{H}_{51} \mathrm{~N}_{4} \mathrm{O}_{4} \mathrm{~S}$ & 551.3626 & 1.5 & $\mathrm{C}_{16} \mathrm{H}_{30} \mathrm{O}_{2}$ & unknown \\
\hline & 9 & 9.8 & 815.4859 & $\mathrm{C}_{41} \mathrm{H}_{67} \mathrm{~N}_{8} \mathrm{O}_{7} \mathrm{~S}$ & 815.4848 & 1.3 & $\mathrm{C}_{28} \mathrm{H}_{46} \mathrm{~N}_{4} \mathrm{O}_{5}$ & 6 \\
\hline & - & 10.1 & 819.5144 & $\mathrm{C}_{41} \mathrm{H}_{71} \mathrm{~N}_{8} \mathrm{O}_{7} \mathrm{~S}$ & 819.5161 & 2.0 & $\mathrm{C}_{28} \mathrm{H}_{50} \mathrm{~N}_{4} \mathrm{O}_{5}$ & unknown \\
\hline \multirow{3}{*}{$\begin{array}{l}\text { Photorhabdus } \\
\text { temperata subsp. } \\
\text { thracensis } \\
\text { DSM } 15199\end{array}$} & - & 8.0 & 493.2258 & $\mathrm{C}_{27} \mathrm{H}_{33} \mathrm{~N}_{4} \mathrm{O}_{3} \mathrm{~S}$ & 493.2268 & 2.0 & $\mathrm{C}_{14} \mathrm{H}_{14} \mathrm{O}$ & unknown \\
\hline & - & 9.5 & 489.2525 & $\mathrm{C}_{25} \mathrm{H}_{37} \mathrm{~N}_{4} \mathrm{O}_{4} \mathrm{~S}$ & 489.2530 & 3.9 & $\mathrm{C}_{12} \mathrm{H}_{16} \mathrm{O}_{2}$ & unknown \\
\hline & - & 10.7 & 551.3617 & $\mathrm{C}_{29} \mathrm{H}_{51} \mathrm{~N}_{4} \mathrm{O}_{4} \mathrm{~S}$ & 551.3626 & 1.5 & $\mathrm{C}_{16} \mathrm{H}_{30} \mathrm{O}_{2}$ & unknown \\
\hline
\end{tabular}

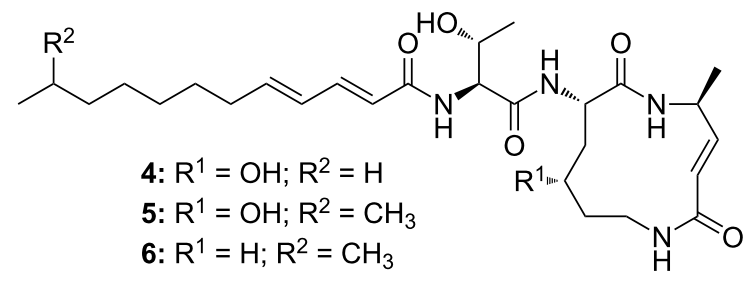

1. azidation

2. azide enrichment procedure

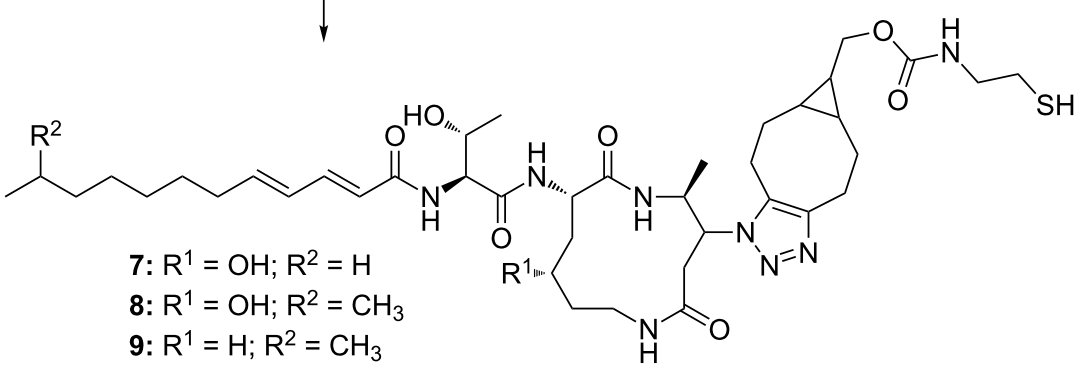

Scheme 2: Structures of glidobactin derivatives (glidobactin A (4), cepafungin I (5) and luminmycin D (6)) before and after azidation and azide enrichment procedure $(\mathbf{7}, \mathbf{8}, \mathbf{9})$. The $\mathrm{MS}^{2}$ spectrum indicates that azidation of glidobactins only took place on the reactive site that is also targeted by the proteasome (Supporting Information File 1, Figure S11) [24].

only been detected from infected insects [25], low-salt growth media [24] or by heterologous expression of the respective gene cluster in E. coli [26]. Their identification in this study was confirmed with pure glidobactin A (4) showing the same azide reactivity and retention time compared to 4 from the crude extract (Supporting Information File 1, Figure S10). The comparison of the MS/MS spectra of natural and azidated 4 revealed that the reaction took place at the ring-double bond that is also attacked by the threonine in the proteasome (Supporting Information File 1, Figure S11). To the best of our knowledge, this is the first detection of glidobactins in a supernatant of Photorhabdus under standard laboratory conditions, which points out once again the advantage of the enrichment step allowing the detection of otherwise barely detectable components in complex mixtures. A determination of the detection limit for pure glidobactin A (4) added into LB medium revealed a detection limit of
$10 \mu \mathrm{g} / \mathrm{L}(\approx 20 \mathrm{nmol} / \mathrm{L})$ (Supporting Information File 1, Figure $\mathrm{S} 12)$ and was comparable to the detection limit of the epoxide (Supporting Information File 1, Figure S4).

\section{Conclusion}

The combination of the reactivity-guided introduction of an azide functionality into electrophilic natural products and the subsequent azide enrichment on a solid phase facilitates the detection of epoxides and $\alpha, \beta$-unsaturated enones in XAD extracts of Photorhabdus. Epoxystilbene (1) and glidobactins have never been observed before in XAD extracts of Photorhabdus grown under standard conditions. Most likely this is due to very low production levels of these compounds thus illustrating the power of this method. We deem that many more electrophilic compounds were just overlooked in the past due to their low concentrations. In combination with labeling 
experiments even the nature of the parent natural product could be revealed. Moreover, a possible scale-up of this procedure should enable the preparative purification of yet unidentified compounds as well as the structural confirmation of the identified structures. This approach can also be applied to extracts of other bacteria, fungi and plants and can give at least hints on new electrophilic natural products, where their reactivity against azide might also reflect their biological activity.

\section{Supporting Information}

\section{Supporting Information File 1}

Materials, methods and supplementary figures.

[http://www.beilstein-journals.org/bjoc/content/ supplementary/1860-5397-13-43-S1.pdf]

\section{Acknowledgements}

The authors are grateful to Dr. A. J. Perez for providing CARR and helpful discussions, as well as Lei Zhao for providing purified glidobactin A. This work was supported by a European Research Council starting grant under grant agreement number 311477.

\section{References}

1. Newman, D. J.; Cragg, G. M. J. Nat. Prod. 2012, 75, 311-335. doi:10.1021/np200906s

2. Cragg, G. M.; Newman, D. J. Biochim. Biophys. Acta 2013, 1830, 3670-3695. doi:10.1016/j.bbagen.2013.02.008

3. Laupacis, A.; Keown, P. A.; Ulan, R. A.; McKenzie, N.; Stiller, C. R. Can. Med. Assoc. J. 1982, 126, 1041-1046.

4. Kahan, B. D. Tex. Heart Inst. J. 1982, 9, 253-266.

5. Rutledge, P. J.; Challis, G. L. Nat. Rev. Microbiol. 2015, 13, 509-523. doi:10.1038/nrmicro3496

6. Miles, C. O.; Sandvik, M.; Nonga, H. E.; Rundberget, T.; Wilkins, A. L.; Rise, F.; Ballot, A. Environ. Sci. Technol. 2012, 46, 8937-8944. doi:10.1021/es301808h

7. Cox, C. L.; Tietz, J. I.; Sokolowski, K.; Melby, J. O.; Doroghazi, J. R.; Mitchell, D. A. ACS Chem. Biol. 2014, 9, 2014-2022. doi: $10.1021 / \mathrm{cb} 500324 \mathrm{n}$

8. Carlson, E. E.; Cravatt, B. F. J. Am. Chem. Soc. 2007, 129, 15780-15782. doi:10.1021/ja0779506

9. Carlson, E. E.; Cravatt, B. F. Nat. Methods 2007, 4, 429-435. doi:10.1038/nmeth1038

10. Marfey, P. Carlsberg Res. Commun. 1984, 49, 591-596. doi:10.1007/BF02908688

11. Odendaal, A. Y.; Trader, D. J.; Carlson, E. E. Chem. Sci. 2011, 2, 760-764. doi:10.1039/C0SC00620C

12. Castro-Falcón, G.; Hahn, D.; Reimer, D.; Hughes, C. C. ACS Chem. Biol. 2016, 11, 2328-2336. doi:10.1021/acschembio.5b00924

13. Jeon, H.; Lim, C.; Lee, J. M.; Kim, S. Chem. Sci. 2015, 6, 2806-2811. doi:10.1039/C5SC00360A

14. Ross, C.; Scherlach, K.; Kloss, F.; Hertweck, C. Angew. Chem., Int. Ed. 2014, 53, 7794-7798. doi:10.1002/anie.201403344
15. Pérez, A. J.; Wesche, F.; Adihou, H.; Bode, H. B. Chem. - Eur. J. 2016, 22, 639-645. doi:10.1002/chem.201503781

16. Rowland, E. B.; Rowland, G. B.; Rivera-Otero, E.; Antilla, J. C. J. Am. Chem. Soc. 2007, 129, 12084-12085. doi:10.1021/ja0751779

17. Lupattelli, P.; Bonini, C.; Caruso, L.; Gambacorta, A. J. Org. Chem. 2003, 68, 3360-3362. doi:10.1021/jo034133p

18. Hu, K.; Li, J.; Li, B.; Webster, J. M.; Chen, G. Bioorg. Med. Chem. 2006, 14, 4677-4681. doi:10.1016/j.bmc.2006.01.025

19. Kontnik, R.; Crawford, J. M.; Clardy, J. ACS Chem. Biol. 2010, 5, 659-665. doi:10.1021/cb100117k

20. Crawford, J. M.; Kontnik, R.; Clardy, J. Curr. Biol. 2010, 20, 69-74. doi:10.1016/j.cub.2009.10.059

21. Eleftherianos, I.; Boundy, S.; Joyce, S. A.; Aslam, S.; Marshall, J. W.; Cox, R. J.; Simpson, T. J.; Clarke, D. J.; ffrench-Constant, R. H.; Reynolds, S. E. Proc. Natl. Acad. Sci. U. S. A. 2007, 104, 2419-2424. doi:10.1073/pnas.0610525104

22. Oka, M.; Nishiyama, Y.; Ohta, S.; Kamei, H.; Konishi, M.; Miyaki, T.; Oki, T.; Kawaguchi, H. J. Antibiot. 1988, 41, 1331-1337. doi:10.7164/antibiotics.41.1331

23. Terui, Y.; Nishikawa, J.; Hinoo, H.; Kato, T.; Shoji, J. J. Antibiot. 1990, 43, 788-795. doi:10.7164/antibiotics.43.788

24. Stein, M. L.; Beck, P.; Kaiser, M.; Dudler, R.; Becker, C. F. W.; Groll, M. Proc. Natl. Acad. Sci. U. S. A. 2012, 109, 18367-18371. doi:10.1073/pnas.1211423109

25. Theodore, C. M.; King, J. B.; You, J.; Cichewicz, R. H. J. Nat. Prod. 2012, 75, 2007-2011. doi:10.1021/np300623x

26. Fu, J.; Bian, X.; Hu, S.; Wang, H.; Huang, F.; Seibert, P. M.; Plaza, A.; Xia, L.; Müller, R.; Stewart, A. F.; Zhang, Y. Nat. Biotechnol. 2012, 30, 440-446. doi:10.1038/nbt.2183

\section{License and Terms}

This is an Open Access article under the terms of the Creative Commons Attribution License (http://creativecommons.org/licenses/by/4.0), which permits unrestricted use, distribution, and reproduction in any medium, provided the original work is properly cited.

The license is subject to the Beilstein Journal of Organic Chemistry terms and conditions:

(http://www.beilstein-journals.org/bjoc)

The definitive version of this article is the electronic one which can be found at: doi:10.3762/bjoc. 13.43 